\title{
Efficient synthesis of ethyl 2-(oxazolin-2-yl)alkanoates via ethoxycarbonylketene-induced electrophilic ring expansion of aziridines
}

\author{
Yelong Lei and Jiaxi $\mathrm{Xu}^{*}$
}

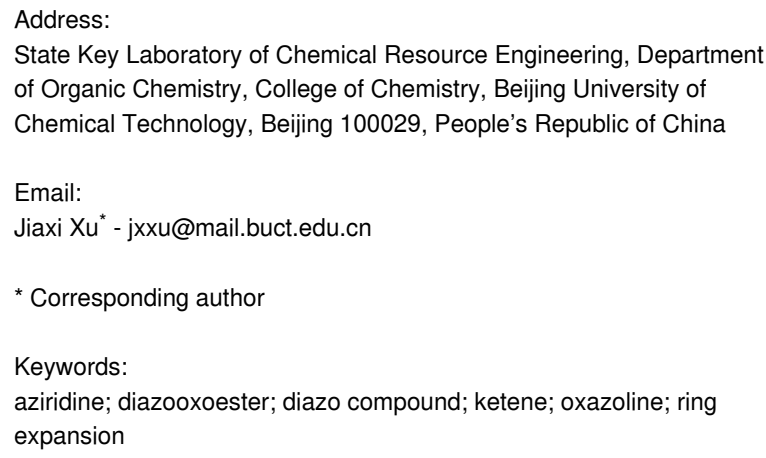

\author{
Beilstein J. Org. Chem. 2022, 18, 70-76. \\ https://doi.org/10.3762/bjoc. 18.6 \\ Received: 16 November 2021 \\ Accepted: 21 December 2021 \\ Published: 05 January 2022 \\ Associate Editor: B. Nay \\ (C) 2022 Lei and Xu; licensee Beilstein-Institut. \\ License and terms: see end of document.
}

\begin{abstract}
Alkyl 2-diazo-3-oxoalkanoates generate alkoxycarbonylketenes, which undergo an electrophilic ring expansion with aziridines to afford alkyl 2-(oxazolin-2-yl)alkanoates in good to excellent yields under microwave heating. The method is a convenient and clean reaction without any activators and catalysts and can be also applied in the synthesis of 2-(oxazolin-2-yl)alkanamides and 1-(oxazolin-2-yl)alkylphosphonates.
\end{abstract}

\section{Introduction}

Oxazoline derivatives are an important class of nitrogen and oxygen-containing five-membered unsaturated heterocycles [1] and widely exist in some natural products [2] and pharmaceuticals [3], such as in the antitumor epi-oxazoline halipeptin D isolated from marine organisms [4], in the cytotoxic natural depsipeptide brasilibactin A [5], and cyclohexapeptide bistratamide A [6] (Figure 1). Oxazoline is also one of the crucial coordinating groups in symmetric and asymmetric ligands widely applied in various organic transformations [7]. Especially, bisoxazolines are a kind of widely applied chiral ligands in diverse transition metal-participating asymmetric catalysis [8-10].
Several methods have been developed for the efficient synthesis of oxazoline derivatives $[11,12]$. They mainly include (1) cyclization of 2-amidoethyl halides or sulfonates, which are prepared from carboxylic acid derivatives and vicinal amino alcohols [8-10] (Scheme 1a); (2) direct condensation of carboxylic acid derivatives or nitriles with vicinal amino alcohols [13-15] (Scheme 1a); (3) oxidative condensation of aldehydes with vicinal amino alcohols [16] (Scheme 1b); (4) cyclization of $\mathrm{N}$-allylamides in the presence of electrophilic reagents or radical initiators or catalysts [17] (Scheme 1c); (5) direct synthesis from alkenes and amides or nitriles in the presence of electrophilic reagents $[18,19]$ (Scheme 1d). Aziridines can be 


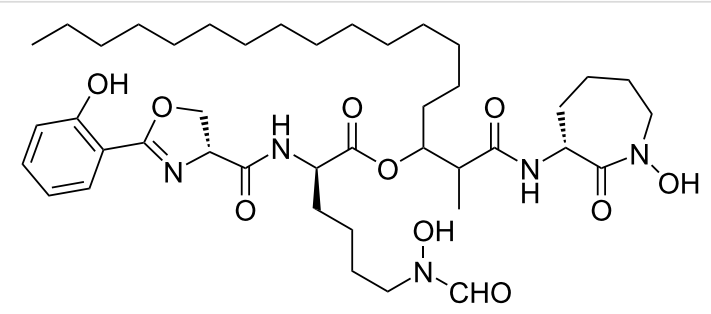

cytotoxic natural depsipeptide brasilibactin A

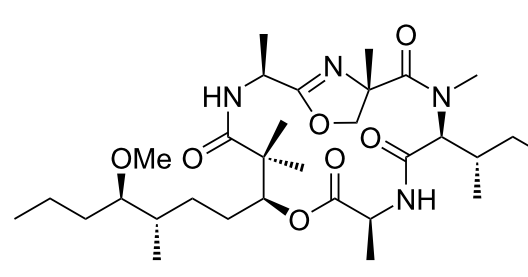

antitumor epi-oxazoline halipeptin D isolated from marine organisms<smiles>CC(C)C(C)NC(=O)[C@H]1N=C([C@H](NC(=O)C2CSC(C(Cc3ccccc3)NC(=O)C3CSC=N3)=N2)C(C)C)O[C@@H]1C</smiles>

bistratamide $\mathrm{A}$ cytotoxic cyclohexapeptide

Figure 1: Oxazoline-containing bioactive natural products.

a) synthesis from carboxylic acid derivatives or nitriles and vicinal amino alcohols

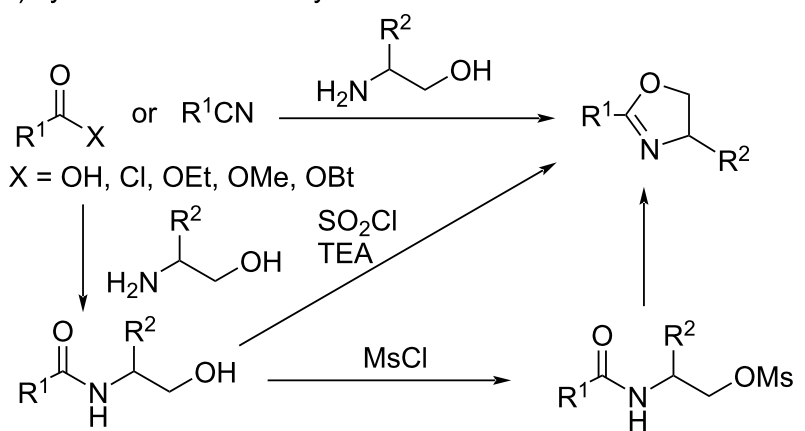

b) synthesis from aldehydes and vicinal amino alcohols

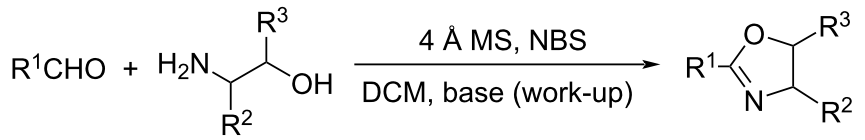

c) synthesis from $\mathrm{N}$-allylamides

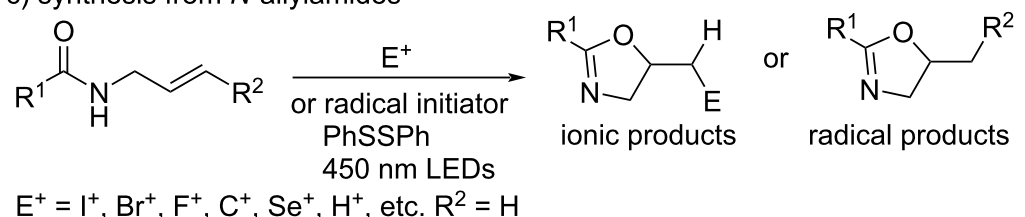

d) synthesis from alkenes and amides or nitriles

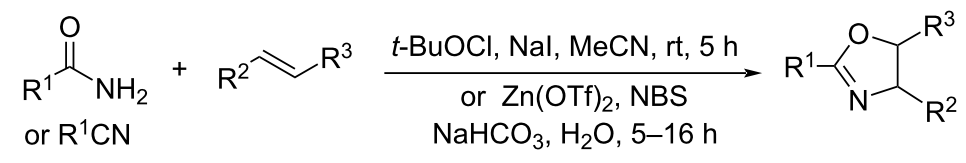

e) this work: synthesis of oxazolines from diazo esters and aziridines

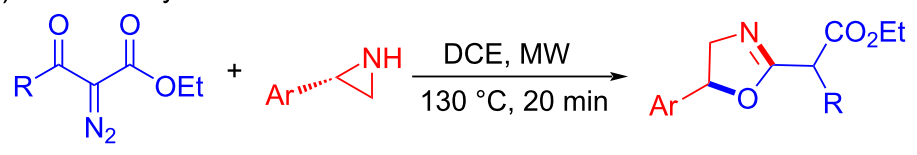


considered as the NCC structural fragment after ring-opening and have been applied in the synthesis of aziridine-imine-containing chiral tridentate ligands [20], 2-alkylideneoxazolidines [21], and $N$-vinylamides [22]. We envisioned that the reaction of ethoxycarbonylketenes and aziridines can be applied for the synthesis of ethyl 2-(oxazolin-2-yl)alkanoates. Herein, we present our convenient and clean synthesis of ethyl 2-(oxazolin2-yl)alkanoates from 2-diazo-3-oxoalkanoates and 2-arylaziridines (Scheme 1e).

\section{Results and Discussion}

The reaction of ethyl 2-diazo-3-oxobutanoate (1a) and 2-phenylaziridine (2a) was first selected as a model reaction to optimize the reaction conditions (Table 1). Diazo ester 1a $(0.36 \mathrm{mmol})$ and aziridine $\mathbf{2 a}(0.3 \mathrm{mmol})$ in 1,2-dichloroethane (DCE, $1 \mathrm{~mL}$ ) were heated at $110^{\circ} \mathrm{C}$ for $30 \mathrm{~min}$ with microwave heating, affording the desired product 3aa in $41 \%$ yield with remaining starting materials $\mathbf{1 a}$ and $\mathbf{2 a}$ (Table 1, entry 1). The reaction was further conducted at elevated temperatures $120{ }^{\circ} \mathrm{C}, 130{ }^{\circ} \mathrm{C}$, and $140{ }^{\circ} \mathrm{C}$, giving the product 3aa in $64 \%$,
$68 \%$, and $70 \%$, respectively (Table 1 , entries $2-4$ ). Similar yields were obtained at $130{ }^{\circ} \mathrm{C}$ and $140{ }^{\circ} \mathrm{C}$. The yield increased to $71 \%$ when the reaction time was shortened to $20 \mathrm{~min}$ (Table 1, entry 5). Further shortening the reaction time to 10 min resulted in the yield to drop to $66 \%$ (Table 1, entry 6). Changing the ratio of diazo ester 1a and aziridine 2a did not improve the yield (Table 1, entries 7-9). Solvent screening indicated that the same yield of $71 \%$ was obtained in toluene (Table 1, entry 13). However, lower yields were obtained in $\mathrm{MeCN}$, THF, and 1,4-dioxane (Table 1, entries 10-12). Further optimizations in toluene were carried out. However, the yield was not further improved, even if the reaction was conducted at $140{ }^{\circ} \mathrm{C}$ and $150{ }^{\circ} \mathrm{C}$ (Table 1, entries 15-18). In each of these cases, a 1:1 mixture of diastereomeric product 3aa was obtained. Finally, considering that the yield is slightly higher at $130{ }^{\circ} \mathrm{C}$ than that at $140{ }^{\circ} \mathrm{C}$ and DCE shows better solubility to all substrates than toluene, the optimal reaction conditions were selected as: diazo ester $\mathbf{1 a}(0.36 \mathrm{mmol})$ and $\mathbf{2 a}(0.3 \mathrm{mmol})$ in DCE $(1 \mathrm{~mL})$ were heated at $130{ }^{\circ} \mathrm{C}$ for 20 min with microwave heating.

Table 1: Optimization of reaction conditions ${ }^{\mathrm{a}}$

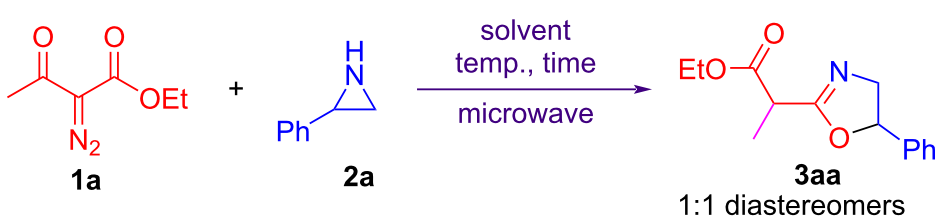

\begin{tabular}{|c|c|c|c|c|c|}
\hline Entry & Diazo ester 1a (mmol) & Solvent & Temp. $\left({ }^{\circ} \mathrm{C}\right)$ & Time (min) & Yield $(\%)^{b}$ \\
\hline 1 & 0.36 & DCE & 110 & 30 & 41 \\
\hline 2 & 0.36 & DCE & 120 & 30 & 64 \\
\hline 3 & 0.36 & DCE & 130 & 30 & 68 \\
\hline 4 & 0.36 & DCE & 140 & 30 & 70 \\
\hline 5 & 0.36 & DCE & 130 & 20 & 71 \\
\hline 6 & 0.36 & DCE & 130 & 10 & 66 \\
\hline 7 & 0.30 & DCE & 130 & 20 & 63 \\
\hline 8 & 0.45 & DCE & 130 & 20 & 53 \\
\hline 9 & 0.60 & DCE & 130 & 20 & 62 \\
\hline 10 & 0.36 & $\mathrm{MeCN}$ & 130 & 20 & 48 \\
\hline 11 & 0.36 & THF & 120 & 20 & 10 \\
\hline 12 & 0.36 & 1,4-dioxane & 130 & 20 & 50 \\
\hline 13 & 0.36 & toluene & 130 & 20 & 71 \\
\hline 15 & 0.36 & toluene & 130 & 30 & 67 \\
\hline 16 & 0.45 & toluene & 130 & 30 & 56 \\
\hline 17 & 0.45 & toluene & 140 & 30 & 62 \\
\hline 18 & 0.45 & toluene & 150 & 30 & 55 \\
\hline
\end{tabular}

aAll reactions were conducted with $1 \mathbf{a}$ and $\mathbf{2 a}(0.3 \mathrm{mmol})$ in solvent $(1.0 \mathrm{~mL})$ in a sealed $10 \mathrm{~mL}$ microwave tube and were stirred under microwave heating. ${ }^{\mathrm{b}}$ The yield was determined by ${ }^{1} \mathrm{H}$ NMR with 1,3,5-trimethoxybenzene as an internal standard. 
With the optimal reaction conditions in hand, we evaluated the scopes and generalities of both diazo esters $\mathbf{1}$ and aziridines $\mathbf{2}$ (Scheme 2). Different 2-arylaziridines 2 were reacted with diazo ester 1a, affording oxazolines 3aa-ai in 60-91\% yields. No obvious electronic effect was observed. Steric bulky 2-(2chlorophenyl)aziridine (2f) gave the desired product 3af in the highest yield of $91 \%$. Steric 2-(naphth-1-yl)aziridine (2i) also exhibited a higher yield than 2-(naphth-2-yl)aziridine (2h). However, aliphatic aziridine 2-benzylaziridine (2j) did not give the corresponding product 3aj when it reacted with diazo ester 1a although 1a decomposed under the reaction conditions. The reactions of different diazo esters $\mathbf{1}$ and aziridine $2 \mathbf{i}$ were per-<smiles>[R]C(=O)C(=[W])C(=O)OCC</smiles><smiles>CCOC(=O)C(C)C1=NCC(c2cccc(Cl)c2)O1</smiles3ae, $60 \%$<smiles>CCOC(=O)C(C)C1=NCC(c2ccc3ccccc3c2)O1</smiles>

3ah, $71 \%$<smiles>[R]C(C(=O)OCC)C1=NCC([Ga])O1</smiles>

3

1:1 diastereomers<smiles>CCOC(=O)C(C)C1=NCC(c2ccccc2Cl)O1</smiles>

3af, $91 \%$<smiles>CCOC(=O)C(C)C1=NCC(c2cccc3ccccc23)O1</smiles>

3ai, $82 \%$<smiles>CCOC(=O)C(C)C1=NCC(Cc2ccccc2)O1</smiles>

3aj, $0 \%$<smiles>COC(=O)C(C)C1=NCC(c2cccc3ccccc23)O1</smiles>

3bi, $88 \%$<smiles>CCOC(=O)C(C1=NCC(c2cccc3ccccc23)O1)C1CCCCC1</smiles>

3ei, $90 \%$<smiles>CC(C(=O)N(C)C)C1=NCC(c2cccc3ccccc23)O1</smiles>

3hi, $70 \%$<smiles>CCCC(C(=O)OCC)C1=NCC(c2cccc3ccccc23)O1</smiles>

$3 \mathbf{c i}, 86 \%$<smiles>CCOC(=O)C(Cc1ccccc1)C1=NCC(c2cccc3ccccc23)O1</smiles>

3fi, $85 \%$<smiles>CCOP(=O)(OCC)C(C)C1=NCC(c2cccc3ccccc23)O1</smiles>

$3 \mathrm{ii}, 92 \%$<smiles>CCOC(=O)C(C1=NCC(c2cccc3ccccc23)O1)C(C)C</smiles>

3di, $73 \%$<smiles>C=CCCC(C(=O)OCC)C1=NCC(c2cccc3ccccc23)O1</smiles>

3 gi, $94 \%$

Scheme 2: Scopes of aziridines and diazo esters. 
formed, generating the corresponding oxazolines 3bi-gi in 73-94\% yields. Ethyl 2-diazo-3-oxohept-6-enoate showed the highest activity, affording the desired product 3gi in $94 \%$ yield. One diazo amide, 2-diazo- $N, N$-dimethyl-3-oxobutanamide (1h), was tested with aziridine $\mathbf{2} \mathbf{i}$ as well, giving the desired product 2-(oxazolin-2-yl)propanamide $3 \mathbf{h i}$ in $70 \%$ yield. Similarly, the reaction of diethyl 1-diazo-2-oxopropylphosphonate (1i) and aziridine $2 \mathbf{i}$ gave rise to the corresponding product 1-(oxazolin2-yl)alkylphosphonate 3ii in 92\% yield. In all cases, 1:1 mixtures of diastereomeric products $\mathbf{3}$ were obtained. Compared with previously reported methods, our current method is more convenient and low cost without any activators (such as thionyl chloride, sulfonyl chlorides, NBS, electrophiles, and radical initiators) and catalysts. The current synthetic strategy is a clean reaction and shows widely application in the preparation of 1-(oxazolin-2-yl)alkanoic acid derivatives and dialkyl 1-(oxazolin-2-yl)alkylphosphonates.

On the basis of the experimental results and previous reports $[21,22]$, the reaction mechanism is rationalized as following (Scheme 3). Under microwave heating, diazo esters 1 undergo a Wolff rearrangement to generate ethoxycarbonylketenes $\mathbf{A}$ by loss of nitrogen. The nucleophilic attack of 2-arylaziridine $\mathbf{2}$ on the ketene moiety produces zwitterionic intermediates $\mathbf{B}$, in which the aziridinium is opened to form the benzylic carbocation stabilized through the $\mathrm{p}-\pi$ conjugation. This stabilization is not possible with alkyl groups, explaining why 2-alkylaziridines did not generate the corresponding products. Intermediates $\mathbf{C}$ undergo an intramolecular nucleophilic attack to yield ethyl (oxazolidin-2-ylidene)alkanoates $\mathbf{D}$, which further isomerize to more stable products, ethyl (oxazolin-2-yl)alkanoates 3 .

Interestingly, the reaction of $\alpha$-diazo- $\beta$-diketones and 2-arylaziridines generated 2-(2-oxoalkylidene)oxazolidines [21], while the current reaction of alkyl $\alpha$-diazo- $\beta$-oxoalkanoates and 2-arylaziridines gave alkyl (oxazolin-2-yl)alkanoates as products, showing different chemoselectivities. 2-Alkylideneoxazolidines and 2-alkyloxazolines are structural isomers and can possibly tautomerize each other. As a more electron-withdrawing group with more electron density on the carbonyl group, a ketone favors the conjugation of the double bond as well as the intramolecular hydrogen bond. Thus, the tautomerization favors to the left direction, forming D-form products, when $\alpha$-diazo- $\beta$-diketones are as starting materials $\left(\mathrm{R}^{1}=\right.$ alkyl and aryl), while it predominates to the right direction, generating 2-(alkoxycarbonyl)methyloxazolines as products, when alkyl $\alpha$-diazo- $\beta$-oxoalkanoates are used in the reaction, showing specific chemoselectivities controlled by the electronic effect (Scheme 4).<smiles>[R]C(=O)C([R])C1=NCC([Al])O1</smiles>

acidity of the $\alpha$-hydrogen basicity of the carbonyl

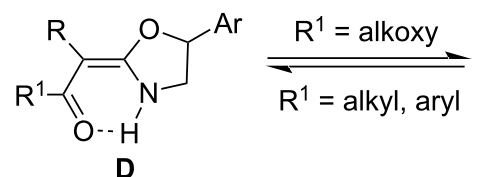<smiles>[R]C(=O)C([R])C1=NCC([Al])O1</smiles>

3

Scheme 4: Direction of tautomerization.

\section{Conclusion}

A new and efficient synthetic method for the synthesis of oxazolines has been developed with alkyl 2-diazo-3-oxoalkanoates and 2-arylaziridines as starting materials. Alkyl 2-diazo-3oxoalkanoates first generate alkoxycarbonylketenes, which<smiles>[R]C(=O)C(=N)C(=O)OCC</smiles><smiles>[R]C(=O)OCC</smiles>

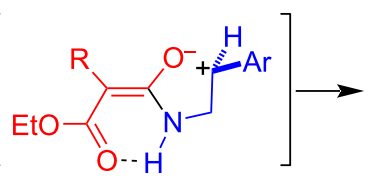

C<smiles>[R]C1=C2O[C@H]([Al]C#CC)CN2C[OH+]1</smiles>

D<smiles>[R]C(C(=O)OCC)C1=NC[C@@H]([AlH2])O1</smiles>

3

intimate ion-pair 
undergo an electrophilic ring expansion with aziridines to afford alkyl 2-(oxazolin-2-yl)alkanoates in good to excellent yields under microwave heating. The current method is an activatorand catalyst-free, and clean synthetic strategy and can be applied in the synthesis of 2-(oxazolin-2-yl)alkanamides and 1-(oxazolin-2-yl)alkylphosphonates as well, showing versatile application.

\section{Experimental}

Unless otherwise noted, all materials were purchased from commercial suppliers without further purification. THF was refluxed over $\mathrm{LiAlH}_{4}$; DCE, MeCN, and 1,4-dioxane were refluxed over $\mathrm{CaH}_{2}$; toluene was refluxed over Na with benzophenone as an indicator, and all solvents were freshly distilled prior to use. Flash column chromatography was performed using silica gel (normal phase, 200-300 mesh) from Branch of Qingdao Haiyang Chemical. Petroleum ether (PE) used for column chromatography was the $60-90{ }^{\circ} \mathrm{C}$ fraction, and the removal of residual solvent was accomplished under rotovap. Reactions were monitored by thin-layer chromatography on silica gel GF254 coated $0.2 \mathrm{~mm}$ plates from Institute of Yantai Chemical Industry. Microwave-assisted reactions were conducted on a CEM discovery SP microwave reactor. The plates were visualized under UV light, as well as other TLC stains. ${ }^{1} \mathrm{H}$, ${ }^{13} \mathrm{C}$, and ${ }^{31} \mathrm{P}$ NMR spectra were recorded on a Bruker $400 \mathrm{MHz}$ spectrometer in $\mathrm{CDCl}_{3}$ with solvent peaks as internal standards, for ${ }^{31} \mathrm{P} \mathrm{NMR}, 85 \% \mathrm{H}_{3} \mathrm{PO}_{4}$ as an external standard, and the chemical shifts $(\delta)$ are reported in parts per million (ppm). All coupling constants $(J)$ in ${ }^{1} \mathrm{H}$ NMR are absolute values given in hertz $(\mathrm{Hz})$ with peaks labeled as singlet (s), broad singlet (brs), doublet (d), triplet (t), quartet (q), and multiplet (m). IR spectra ( $\mathrm{KBr}$ pellets, $\mathrm{v}\left[\mathrm{cm}^{-1}\right]$ ) were taken on a Bruker Tensor 27 FTIR spectrometer. HRMS measurements were carried out on a Waters Acquilty UPLC/Quattro Premier mass spectrometer.

Alkyl 2-diazo-3-oxoalkanoates 1 were synthesized by referring our previous procedure $[22,23]$. Their analytic data are identical to previously reported ones 1a,b [23], 1c,d [24], 1e,g [25], 1f [26], 1h [27] and 1i [28]. Aziridines 2 were prepared according to our previous method [21] and their analytic data are identical to previously reported ones $\mathbf{2 a - f}$ [21] and $\mathbf{2 g}$ [29].

\section{General procedure for the synthesis of ethyl 2-(oxazol-2-yl)alkanoates 3}

Diazo compound $1(0.36 \mathrm{mmol})$ and aziridine $2(0.30 \mathrm{mmol})$ were added to DCE $(1.0 \mathrm{~mL})$ in a sealed $10 \mathrm{~mL}$ microwave tube. The resulting solution was stirred at $130{ }^{\circ} \mathrm{C}$ for $20 \mathrm{~min}$ under microwave heating. After the reaction was completed, the resulting mixture was evaporated in vacuo. The crude residue was purified by silica gel column chromatography (PE/EA 2:1, $\mathrm{v} / \mathrm{v}$ ) to give product 3 .

\section{Supporting Information}

\section{Supporting Information File 1}

Analytic data and copies of ${ }^{1} \mathrm{H},{ }^{13} \mathrm{C}$, and ${ }^{31} \mathrm{P}$ NMR spectra of compounds 3 .

[https://www.beilstein-journals.org/bjoc/content/ supplementary/1860-5397-18-6-S1.pdf]

\section{Funding}

This research was supported by the National Natural Science Foundation of China (Nos. 21572017 and 21772010).

\section{ORCID ${ }^{\circledR}$ iDs}

Jiaxi Xu - https://orcid.org/0000-0002-9039-4933

\section{Preprint}

A non-peer-reviewed version of this article has been previously published as a preprint: https://doi.org/10.3762/bxiv.2021.79.v1

\section{References}

1. Tilvi, S.; Singh, K. S. Curr. Org. Chem. 2016, 20, 898-929. doi:10.2174/1385272819666150804000046

2. Davyt, D.; Serra, G. Mar. Drugs 2010, 8, 2755-2780. doi:10.3390/md8112755

3. Bansal, S.; Halve, A. K. Int. J. Pharm. Sci. Res. 2014, 5, 4601-4616.

4. Nicolaou, K. C.; Lizos, D. E.; Kim, D. W.; Schlawe, D.; de Noronha, R. G.; Longbottom, D. A.; Rodriquez, M.; Bucci, M.; Cirino, G. J. Am. Chem. Soc. 2006, 128, 4460-4470. doi:10.1021/ja060064v

5. Tsuda, M.; Yamakawa, M.; Oka, S.; Tanaka, Y.; Hoshino, Y.; Mikami, Y.; Sato, A.; Fujiwara, H.; Ohizumi, Y.; Kobayashi, J. J. Nat. Prod. 2005, 68, 462-464. doi:10.1021/np0496385

6. Degnan, B. M.; Hawkins, C. J.; Lavin, M. F.; McCaffrey, E. J.; Parry, D. L.; Watters, D. J. J. Med. Chem. 1989, 32, 1354-1359. doi:10.1021/jm00126a035

7. Connon, R.; Roche, B.; Rokade, B. V.; Guiry, P. J. Chem. Rev. 2021, 121, 6373-6521. doi:10.1021/acs.chemrev.0c00844

8. Xu, J.; Ma, L.; Jiao, P. Chem. Commun. 2004, 1616-1617. doi:10.1039/b404134h

9. Ma, L.; Jiao, P.; Zhang, Q.; Xu, J. Tetrahedron: Asymmetry 2005, 16, 3718-3734. doi:10.1016/j.tetasy.2005.09.025

10. Ma, L.; Du, D.-M.; Xu, J. J. Org. Chem. 2005, 70, 10155-10158. doi:10.1021/j0051765y

11. Wipf, P. Chem. Rev. 1995, 95, 2115-2134. doi:10.1021/cr00038a013

12. Gaumont, A.-C.; Gulea, M.; Levillain, J. Chem. Rev. 2009, 109, 1371-1401. doi:10.1021/cr800189z

13. Katritzky, A. R.; Cai, C.; Suzuki, K.; Singh, S. K. J. Org. Chem. 2004, 69, 811-814. doi:10.1021/j00355092

14. Mohammadpoor-Baltork, I.; Moghadam, M.; Tangestaninejad, S.; Mirkhani, V.; Hojati, S. F. Catal. Commun. 2008, 9, 1153-1161. doi:10.1016/j.catcom.2007.10.026

15. Li, X.; Zhou, B.; Zhang, J.; She, M.; An, S.; Ge, H.; Li, C.; Yin, B.; Li, J.; Shi, Z. Eur. J. Org. Chem. 2012, 1626-1632. doi:10.1002/ejoc.201101786 
16. Schwekendiek, K.; Glorius, F. Synthesis 2006, 2996-3002. doi:10.1055/s-2006-950198

17. Morse, P. D.; Nicewicz, D. A. Chem. Sci. 2015, 6, 270-274. doi:10.1039/c4sc02331e And cited therein.

18. Minakata, S.; Morino, Y.; Ide, T.; Oderaotoshi, Y.; Komatsu, M. Chem. Commun. 2007, 3279-3281. doi:10.1039/b706572h

19. Hajra, S.; Bar, S.; Sinha, D.; Maji, B. J. Org. Chem. 2008, 73, 4320-4322. doi:10.1021/j08003937

20. Chen, X.; Lin, C.; Du, H.; Xu, J. Adv. Synth. Catal. 2019, 361, 1647-1661. doi:10.1002/adsc.201801545

21. Chen, X.; Huang, Z.; Xu, J. Adv. Synth. Catal. 2021, 363, 3098-3108. doi:10.1002/adsc.202100320

22. Chen, X.; Lei, Y.; Fu, D.; Xu, J. Org. Biomol. Chem. 2021, 19, 7678-7689. doi:10.1039/d1ob01359a

23. Li, S.; Chen, X.; Xu, J. Tetrahedron 2018, 74, 1613-1620. doi:10.1016/j.tet.2018.01.014

24. Wang, X.; Zhang, J.; He, Y.; Chen, D.; Wang, C.; Yang, F.; Wang, W.; Ma, Y.; Szostak, M. Org. Lett. 2020, 22, 5187-5192. doi:10.1021/acs.orglett.0c01811

25. Xie, Y.; Chen, X.; Liu, X.; Su, S.-J.; Li, J.; Zeng, W. Chem. Commun. 2016, 52, 5856-5859. doi:10.1039/c6cc00254d

26. Erhunmwunse, M. O.; Steel, P. G. J. Org. Chem. 2008, 73, 8675-8677. doi:10.1021/j08017523

27. Lv, H.; Shi, J.; Wu, B.; Guo, Y.; Huang, J.; Yi, W. Org. Biomol. Chem. 2017, 15, 8054-8058. doi:10.1039/c7ob01977g

28. Ciszewski, Ł. W.; Durka, J.; Gryko, D. Org. Lett. 2019, 21, 7028-7032. doi:10.1021/acs.orglett.9b02612

29. Eckelbarger, J. D.; Wilmot, J. T.; Epperson, M. T.; Thakur, C. S.; Shum, D.; Antczak, C.; Tarassishin, L.; Djaballah, H.; Gin, D. Y. Chem. - Eur. J. 2008, 14, 4293-4306. doi:10.1002/chem.200701998

\section{License and Terms}

This is an open access article licensed under the terms of the Beilstein-Institut Open Access License Agreement (https://www.beilstein-journals.org/bjoc/terms), which is identical to the Creative Commons Attribution 4.0 International License (https://creativecommons.org/licenses/by/4.0). The reuse of material under this license requires that the author(s), source and license are credited. Third-party material in this article could be subject to other licenses (typically indicated in the credit line), and in this case, users are required to obtain permission from the license holder to reuse the material.

The definitive version of this article is the electronic one which can be found at: https://doi.org/10.3762/bjoc.18.6 